\title{
Energy talk for dummies - what to do when you are stuck?
}

Volume 3 Issue 3 - 2016

\section{Opinion}

Stuck is not a funny word. One thinks of traffic, writers block, dead-end job, perhaps relationships and unfinished

We would like to address 'being stuck' from the perspective of stuck thoughts, not unlike the song that repeats itself over and over again. You may be surprised to know that we generate up to 50,000 thoughts per day and $80 \%$ of them are negative. Seriously, does thought really make a difference? Can a thought really impact on a person's well being?

This is what we do know: As a thought occurs, the billions of neurons in one's brain with its many trillions of connections between those neurons become more likely to re-occur. Thought, as a brain event, travels on a neural circuit that is strengthened with repetition. This pattern of firing becomes automatic, like a well- worn path in the woods.

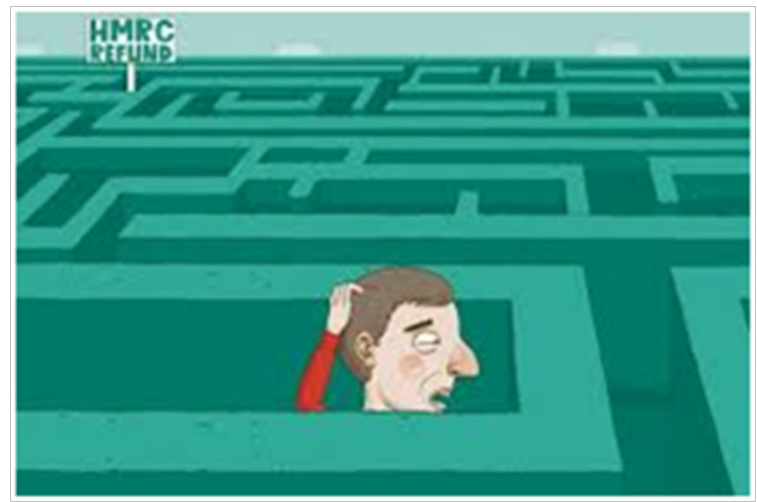

Figure I What to do when you are Stuck.

James $T^{1}$ is a professor emeritus of Materials Science and Engineering at Stanford University. His passion is the exploration, research and discovery in the area of intention to change our physical reality. In his book, Science and Human Transformation, concepts such as subtle energies beyond the four fundamental forces ${ }^{2}$ acting in concert with human consciousness, are explored. His Question is: Can our thoughts actually change our reality? After more than 10years of research with his IIED: Intent Imprint Energy Device, his answer is YES! This device, the IIED, was created and built in his laboratory where he succeeded in recording thought. Specifically, he recorded a meditation with the intent of changing something physical. Four experienced meditators did the imprinting with the 15-minute meditations' focus being "Creator of Universe permission to shift the $\mathrm{pH}$ of water 1 point. "Copies of the recordings were sent to laboratories all over the United States and placed in isolation with a flask of water. Subsequent to exposure of the recorded meditation, the $\mathrm{pH}$ of water shifted one point within 15 minutes. In reviewing his many articles, we contacted him to discuss the research. He happily

\author{
Phyllis Krug, Phyllis Gordon \\ Energy Dialogues, USA
} Correspondence: Phyllis Krug, Physical Therapist, Energy
Dialogues, USA, Tel 973-704-9062,
Email phylliskrug@hotmail.com

Received: October 25, 2015 | Published: March 21, 2016

shared the results however was more excited about what happened after the research. After 10years of studying the effects of intent in changing the $\mathrm{pH}$ of water, he returned to the empty laboratories and placed a flask of water in the laboratory. The $\mathrm{pH}$ changed within 15 minutes. He was eager to discuss the ramification of these findings. His conclusion is that repetition of thought not only has impact on our physical reality; it continues to have impact by being absorbed into the environment.

What does this mean for us? We have the power to generate thoughts that affect our environment, our body, and our home. Our thoughts (are thought to ;-)) make a difference. If as we reported above, $80 \%$ of thoughts are negative, changing our thought patterns is imperative to health. We will continue to write about the many methods effective in changing our thought patterns.

In the meantime: Create and repeat thoughts that work for you!

Then this device - imprinted with the intent - was wrapped in aluminum and sent by overnight shipping to a laboratory 2000miles away, where it was placed beside the "target experiment" and turned on.

So, for example, the electrical device might be imprinted with the idea of raising or lowering the $\mathrm{pH}$ of water. And if the device was turned on in the vicinity of a jar of water, the expectation was that the $\mathrm{pH}$ of the water would be raised or lowered, depending upon the original intent.

In the case of that particular experiment, they were looking for at least a full $\mathrm{pH}$ unit of difference, something large enough that the results could not be attributed to faulty measurement (it's possible to measure $1 / 100$ th or even $1 / 1000$ th of a degree of change in $\mathrm{pH}$, so one full unit is a lot).

Phyllis Krug is a physical therapist with a private practice in Teaneck, NJ and Monsey, NY. Her practice integrates many mind/ 
body and energy therapies. She is available for private consultation, lectures and classes and can be reached at 973-704-9062 www. energydialogues.com

Phyllis Gordon is an occupational therapist in private practice working with infants, children and adults in Tenafly, NJ. For appointments call 201-569-6288 orinfo@phyllisgordon.com or www. phyllisgordon.com

\section{Acknowledgments}

None.

\section{Conflicts of interest}

Author declares there are no conflicts of interest.

\section{Funding}

None.

\section{References}

1. Tiller WA, Kohane MJ, Dibble WE. Can an aspect of consciousness be imprinted into an electronic device? Integr Physiol Behav Sci. 2000;35(2):142-163.

2. http://science.howstuffworks.com/environmental/earth/geophysics/ fundamental-forces-of-nature.htm 